\title{
Analysis Of Factors Affecting Low Coverage Of Exclusive Breast Feeding
}

\author{
Reni Mareta1, Robiul Fitri Masyitoh ${ }^{2}$ \\ 1,2 Fakultas Ilmu Kesehatan, Universitas Muhammadiyah Magelang
}

\begin{tabular}{|c|c|}
\hline Article Info & Abstract \\
\hline $\begin{array}{l}\text { Article History: } \\
\text { Accepted June 3rd } 2018 \\
\text { Key words: } \\
\text { Exclusive Breast Milk }\end{array}$ & $\begin{array}{l}\text { Food is a major factor supporting growth and development for every living } \\
\text { creature. The quantity and composition of the food consumed is tailored to } \\
\text { the needs of each individual. Babies have different food compositions. } \\
\text { According to WHO the best food for babies is given breast milk as soon as } \\
\text { the baby is born until the first } 6 \text { months and continued until the age of } 2 \\
\text { years. This condition can not be achieved if coverage of ASI in each region } \\
\text { is still less. One of the areas whose exclusive coverage is still low is } \\
\text { Magelang City. Data from the health profile of the Magelang City Health } \\
\text { Office in } 2008 \text { mentioned that in Magelang city there was a percentage of } \\
\text { infants who got an exclusive ation of 0.32 percent. Looking at the } \\
\text { phenomenon, researchers are interested to know the factors causing the } \\
\text { low coverage of exclusive breastfeeding in the city of Magelang. This } \\
\text { research is located in the working area of North Magelang Health Center. } \\
\text { The model of this research is by observational analytic with cross sectional } \\
\text { study design design with quantitative approach. Selection of sample by } \\
\text { purposive sampling method with } 30 \text { sample people. This study uses } \\
\text { questionnaires that we will share to samples that have children maximum } \\
2 \text { years old. The questionnaire contains questions about breastfeeding. } \\
\text { From the results of the questionnaire will then be analyzed to determine } \\
\text { the factors causing the low coverage of exclusive breastfeeding in the city } \\
\text { of Magelang. The results of this study indicate there are several factors that } \\
\text { affect the exclusive ation: among others: maternal age, level of education } \\
\text { and mother's work. It is expected that the results of this study could be as } \\
\text { input for the relevant agencies in this case is the Health Department to } \\
\text { make appropriate policies to increase exclusive ASI coverage. }\end{array}$ \\
\hline
\end{tabular}

\section{PENDAHULUAN}

Makanan adalah faktor yang penting untuk menunjang pertumbuhan dan perkembangan anak.Jumlah dan komposisi makanan sangat tergantung pada masa pertumbuhan anak.Usia bayi memerlukan komposisi makanan yang berbeda dari anak yang lebih besar. Menurut WHO menyebutkan bahwa pemberian makanan yang tepat adalah menyusui bayinya segera setelah bayi lahir, dilanjutkan dengan memberikan ASI Eksklusif sampai umur 6 bulan.Pemberian ASI sampai bayi berumur 6 bulan sangat menguntungkan bagi bayi karena bisa memberikan kekebalan bagi bayi. Air susu ibu (ASI) adalah cairan hasil sekresi kelenjar payudara ibu sedangkan ASI eksklusif adalah ASI yang diberikan kepada bayi sejak dilahirkan selama 6 bulan tanpa menambah atau mengganti dengan makanan atau minuman lain (PP RI

Corresponding author:

Reni Mareta 
no 33 tahun 2012). ASI adalah makanan utama dan terbaik untuk bayi yang bersifat alami.ASI mengandung banyak zat gizi yang diperlukan dalam proses pertumbuhan dan perkembangan bayi. Definisi WHO menyebutkan bahwa ASI Eksklusif adalah hanya ASI yang diberikan pada bayi, tanpa cairan atau makanan tambahan kecuali obat dalam bentuk tetes atau sirup sampai usia 6 bulan (WHO (2002) dalam Aprilia, 2009).

Berdasarkan hasil penelitian bayi yang tidak mendapatkan ASI atau mendapatkan ASI tidak eksklusif memiliki resiko kematian lebih besar karena diare yaitu 3,94 dibandingkan bayi yang mendapat ASI eksklusif. Menurut Survey Demografi Kesehatan Indonesia tahun 2007, 46\% kelahiran terjadi di fasilitas kesehatan dan dibantu oleh tenaga kesehatan terlatih. Apabila sepuluh langkah keberhasilan menyusui bisa diterapkan di seluruh fasilitas kesehatan di Indonesia termasuk di rumah sakit, klinik bersalin, maupun yang lainnya maka separuh dari jumlah bayi yang lahir akan mendapatkan inisiasi menyusui dini dan ASI eksklusif.

Keberhasilan pemberian ASI eksklusif ini dipengaruhi oleh beberapa hal.Pemerintah dalam peraturan perundang-undangan juga mengatur secara khusus tentang pemberian ASI eksklusif.Dukungan keluarga sangat berperan dalam kesuksesan pemberian ASI eksklusif.Selain itu dari faktor ibu dan bayi juga mempunyai peranan yang cukup besar dalam pemberian ASI.Beberapa penelitian menyebutkan bahwa ibu yang bekerja cenderung tidak bisa memberikan ASI eksklusifnya. Bayi dengan kondisi-kondisi tertentu misalnya dengan berat badan lahir rendah juga akan bermasalah saat diberikan ASI eksklusif.

\section{METODE}

Model penelitian ini adalah analitik observasional dengan desain penelitian studi cross sectional yang dilakukan dengan pendekatan kuantitatif. Pengambilan sampel dengan metode purposive sampling. Adapun kriteria ekslusi dalam sampel ini adalah ibu yang mempunyai bayi usia lebih dari 6 bulan. Sampel dalam penelitian ini berjumlah 30 orang. Jumlah ini dipilih dengan mempertimbangkan kemudahan dalam memberikan perlakuan dan pengamatan dalam penelitian serta keterbatasan waktu, dana dan sumber daya penelitian.

\section{HASIL}

Penelitian ini melibatkan mahasiswa dalam pengumpulan data. Dalam penelitian ini menggunakan sampel sejumlah $30 \mathrm{ibu}$ yang memiliki balita dengan usia kurang dari 2 tahun. Pendidikan terbanyak dari sampel adalah SMA.

Hasil dari penelitian ini menggambarkan ada beberapa faktor yang mempengaruhi rendahnya cakupan ASI eksklusif adalah usia ibu, tingkat pendidikan ibu dan pekerjaan ibu.

\section{Usia ibu}

Kehamilan merupakan proses yang kebanyakan orang merupakan hal yang sangat dinantikan, tetapi disisi lain banyak pula kehamilan yang terjadi secara tidak diduga atau tidak direncanakan. Kehamilan yang tidak direncanakan biasanya akan dipengaruhi oleh factor usia. Dari responden yang menjadi subyek penelitian ini 21 orang $(70 \%)$ berusia antara 20-35 tahun. Hal ini sangat mempengaruhi poses pemberian Asi eksklusif. Usia tersebut merupakan masa yang palng tepat untuk seorang ibu hamil dan menyusui. Sedangkan 9 orang (30\%) responden berusia diatas 35 tahun. Usia ini merupakan usia resiko tinggi selama ibu tersebut hamil dan melahirkan. Makin tua usia seorang ibu maka akan mempengaruhi juga produksi asi nya. 
2. Tingkat pendidikan ibu

Hasil analisis menyebutkan bahwa ada hubungan antara tingkat pendidikan dengan pemberian asi eksklusif. Semakin tinggi tingkat pendidikan seorang ibu maka semakin baik perilaku pemberian asi eksklusifnya. Makin tinggi pendidikan seorang ibu juga menyebabkan pemahaman seorang ibu terhadap manfaat asi untuk bayinya semakin tinggi, sehingga para ibu termtivasi untuk memberikan asi nya selama minimal 6 bulan pertama. Pendidikan dapat mengubah pengathuan, sikap dan perilaku seseorang.

\section{Pekerjaan ibu}

Hasil penelitian ini menunjukan hasil bahwa ada hubungan antara ibu yang bekerja dengan ketercapaian pemberian asi eksklusif. Dari hasil penelitian ini menyebutkan bahwa ibu yang bekerja menunjukkan kemampuan yang rendah dalam pemberian asi eksklusif. Kebanyakan ibu bekerja masih menganggap adanya asi yang basi dan dapat menyebabkan sakit pada anaknya, sehingga mereka lebih baik membuang asi nya. Akibatnya bayi yang ditinggal hanya mendpatkan as eksklusif. Banyak ibu yang belum memehami tentang bagaimana menyimpan asi yang aman selama ibu bekerja.

\section{SIMPULAN}

Faktor yang mempengaruhi ketercapaian pemberian Asi eksklusif yaitu: usia ibu, tingkat pendidikan ibu dan umur ibu. Dari hasil penelitian ini penulis dapat menyarankan kepada ibu agar merencanakan kehamilan dengan baik sehingga usia ibu masih ideal atau tidak masuk ibu resiko tinggi. Penulis juga menyarankan kepada pelayanan kesehatan terkait untuk memberikan penyuluhan kepada ibu menyusui yang sudah bekerja tentang bagaimana menyimpan Asi yang baik.

\section{REFERENSI}

Aprilia, Y. Analisis Sosialisasi Program Inisiasi Menyusu Dini Dan Asi Eksklusif Kepada Bidan Di Kabupaten Klaten. Tesis UniversitasDiponegoro Semarang 2009.

Baskoro, A, 2008.ASI Panduan Praktis Ibu menyusui, Banyu media

Dahlan, S. Statistik Untuk Kedokteran dan Kesehatan ed.3.Jakarta : Salemba Medika

Depkes, 2005.Manajemen Laktasi. Buku Panduan Bagi Bidan dan Petugas Kesehatan di Puskesmas. Jakarta: Direktorat Jenderal Bina Kesehatan Masyarakat.

Fikawati, S. dan Syafiq, A. Kajian Implementasi Dan Kebijakan Air Susu Ibu Eksklusif Dan Inisiasi Menyusu Dini Di Indonesia.Makara, kesehatan, vol. 14, no. 1, juni 2010: 17-24

Gupta, A., 2007. Initiating breastfeeding within one hour of birth. Presented at Thirty Fourth Session of the Standing Committee on Nutrition

Kurniawati, D., 2005. Hubungan Antara Pengetahuan Gizi Ibu, Tingkat Konsumsi Energi dan Status Gizi Balita di Desa Tawangharjo Kecamatan Widarijaksa Kabupaten Pati Tahun 2005. Skripsi diterbitkan. Semarang: Universitas Semarang

Mareta, Hidayah, 2012. Optimalisasi dukungan Suami Terhadap Pemberian Asi Eksklusi pada Ibu Menyusui.

Laporan Riset Kesehatan Dasar 2010. Badan Penelitian dan Pengembangan Kesehatan

Pedoman penulisan Tesis dan Disertasi ed.4. Program Pascasarjana Universitas Hasanudin Makassar 2009

Roesli, U., 2005. Mengenal ASI Ekslusif. Jakarta : PT Pustaka Pembangunan Swadaya Nusatara

Zainuddin, 2008. Pengaruh Konseling Ibu Hamil Terhadap Inisiasi Menyusu Dini Di Kabupaten Pangkep Tahun 2008. Tesis tidak diterbitkan. Program Pascasarjana Universitas Hasanuddin Makassar 